\title{
Surgical Treatment of Marginal Osteochondral Impaction in Acetabular Fractures
}

\author{
Yousuf M Khira \\ Assistant professor, orthopedic surgery department \\ Faculty of Medicine, Zagazig University; Egypt \\ yousufmmkh@gmail.com
}

\begin{abstract}
Purpose: clinical and radiological evaluation of the results of the technique of elevation and grafting of osteochondral marginal impaction fragment of posterior wall acetabular fractures and complications assessment in follow up period 1-3 years.

Methods: Twenty patients were available for this study had fracture acetabulum with marginal impaction fragment. Elevation, reduction and bone graft impaction of the defect was the technique in all cases. Follow up was 1-3 years. Evaluation of patient was done clinically and radiologically.

Results: Radiologically, according to the Matta's criteria of reduction quality there were anatomic reduction in 16 patients (80\%), and satisfactory reduction in 4 patients(20\%). Clinical assessments based on modified Merle d'Aubigné and Postel score include 4 (20\%) excellent scores and 12 (80\%) good scores, and 3 (15\%) fair results, and poor in one patient who had revision by total hip replacement.

Conclusion: Diagnose of marginal impaction fragment preoperatively makes operative technique by elevation, reduction, bone graft packing, and fixation become mandatory to obtain anatomic reduction and favorable outcome. This technique should be completed before final fixation of the main fracture acetabulum.
\end{abstract}

Key words: fracture, acetabulum, marginal impaction, surgical

\section{INTRODUCTION}

Surgical treatment with open reduction and internal fixation (ORIF) of the acetabular fractures was introduced in the 1960s through the efforts of Judet and Letournel in 1960s [1\&2] and became the treatment of choice for displaced acetabular fractures. In posterior fractures or fracture dislocations of the acetabulum there is a type of injury called Marginal Osteochondral Impaction (MOI) where an osteochondral rotated impacted fragment in the posteromedial acetabulum that causes joint defect and loss of congruity. If not reduced or treated conservatively, this fragment can cause secondary osteoarthritis due to instability and loss of congruity of the hip joint[3\&4]. In sub classification of A 0 posterior wall fractures, the marginal impaction locates in type A1.3(C) [5-8]. In this prospective study, evaluation of the results of twenty acetabular fractures with MOI clinically and radiologically in a mean follow up period of 24 months (range: 12-36 months)so that eventually the prognostic value of MOI in our practicewill be clear.

\section{PATIENTS AND METHODS}

Twenty patients with fracture acetabulum including marginal impaction fragment were treated through open reduction and internal fixation with reconstruction of the articular surface in the period from January 2009 to May 2013. Follow up was one year minimum period. There were (14) male patients (70\%) and (6) females (30\%), with mean age of (32.9) standard of deviation was (10.55) ranged from (21-58 years). In twelve patients $(60 \%)$, the mechanism of injury was car accident, falling from height in five $(25 \%)$, and motorcycle accident in three patients (15\%). The left side was affected in eleven patients (55\%) and the right side in nine (45\%). 
Isolated fracture acetabulum was found in seven patients (35\%), and associated injuries in thirteen (65\%). Six ipsilateral femoral fractures were treated before acetabular fixation. There were four head injuries and three cases with preoperative sciatic nerve injuries. According to Letournel and Judet classification [1], there were eight cases posterior wall fractures, six posterior column and posterior wall fractures, and.6 transverse and posterior wall fractures.Radiological assessment included plain X-rays (A P view of the pelvis showing hips, obturator and iliac oblique views). CT scans coronal and sagittal and computer 3D reconstructions were done for all cases preoperative and in seven cases postoperative to assess reduction and joint congruity. Closed reduction of dislocation was done in six cases presented by fracture dislocation in a mean time of 24 hours (12-36 hours) after injury under general anesthesia and assessment of stability was done clinically and radiologically.

The indications for surgery were displacement of fractures, Irreducible fracture-dislocation, posterior wall fracture with osteochondral fragment and nonconcentric reduction of the femoral head. All patients received DVT prophylaxis by 40 I.U. of enoxaparin sodium to be stopped 12 hours before surgery and then continued for 2 weeks after surgery. Prophylactic broad spectrum antibiotic was given at night of surgery and postoperatively for 10 days, and urethral catheter was introduced before surgery in all patients. The mean time elapsed from injury to operation was of 10 days (range 3-20 days).

\section{SURGICAL TECHNIQUE}

All patients were operated on under spinal anesthesia in lateral position using KockerLangenbeck approach. In three patients trochanteric osteotomy modification of the approach was added. After exposure, sciatic nerve protection reduction and temporary securing posterior column element or the transverse fracture, the fragments were delineated and cleared of debris while maintaining soft-tissue attachments when almost possible to preserve blood supply to the bone. The posterior wall fragments were then reflected on their softtissue hinge, exposing the underlying femoral head. This was done through capsular tear which extending outward from the margins of the fractured posterior wall segment. When a fragment of the posterior wall was incarcerated within the joint with its capsular attachments intact, a right-angle clamp was used to hookit preserving its blood supply intact.
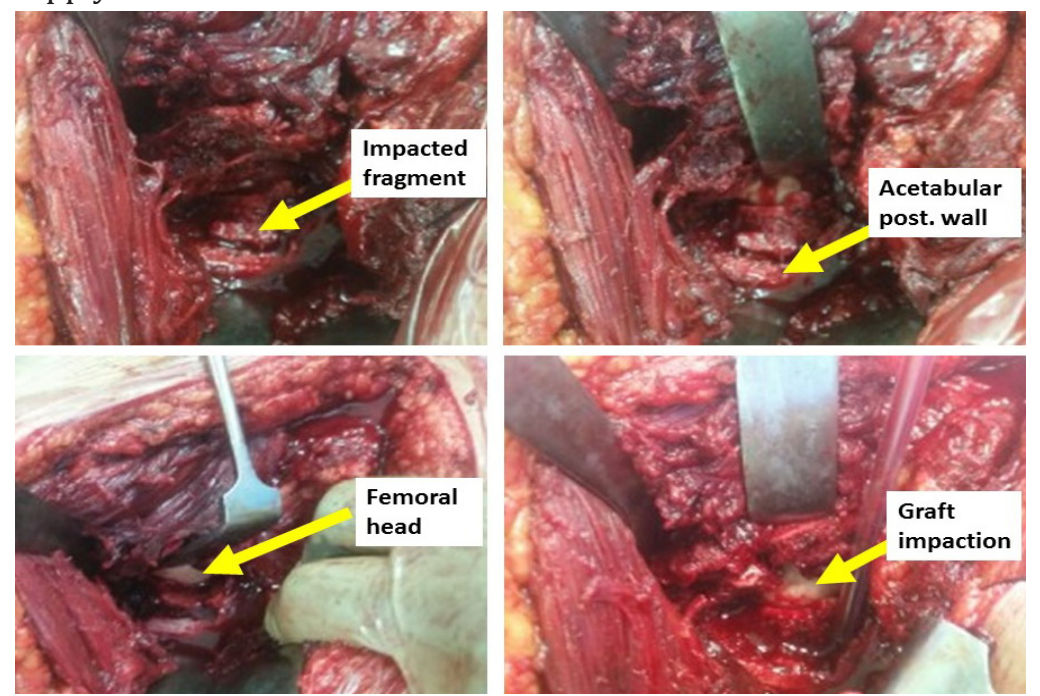

Figure1. Intraoperative photos showing the impacted fragment and head of the femur in exposure before reconstruction.

Disimpaction of the MOI fragment was then done followed by its elevation and derotation to realign it with the normal curvature of the articular surface of the acetabulum. The gap created in the cancellous bone after disimpaction of MOI fragment was firmly packed with cancellous bone graft taken from a small cortical window in the posterior portion the greater trochanter except in cases withtrochanteric osteotomy the graft was obtained from the osteotomy site (Figure 2); [9]. Lag screw fixation of the posterior wall and plate fixation of the 
posterior column were then completed as fracture description. Closure of the wound with interrupted sutures over suction drains were used routinely for all patients. Parenteral broad spectrum cephalosporin antibiotics were used for 1 week, followed by oral antibiotics for 2 weeks.

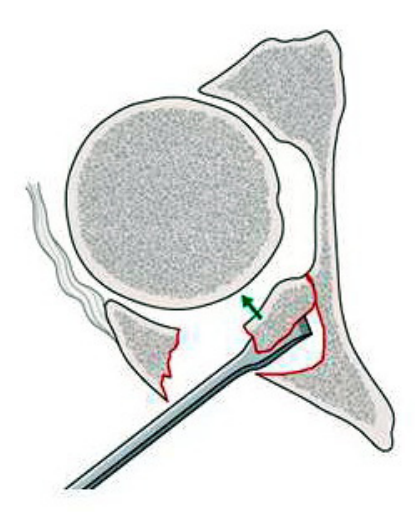

A

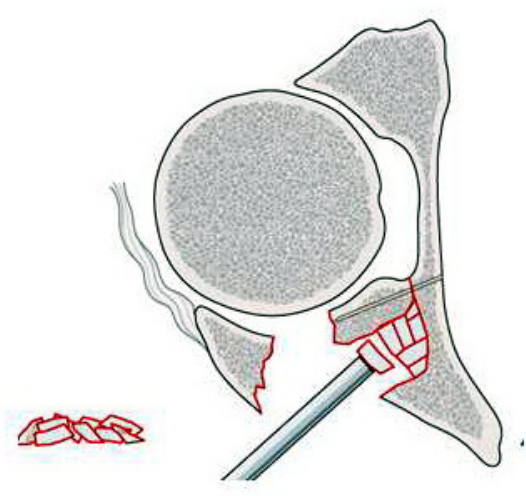

B

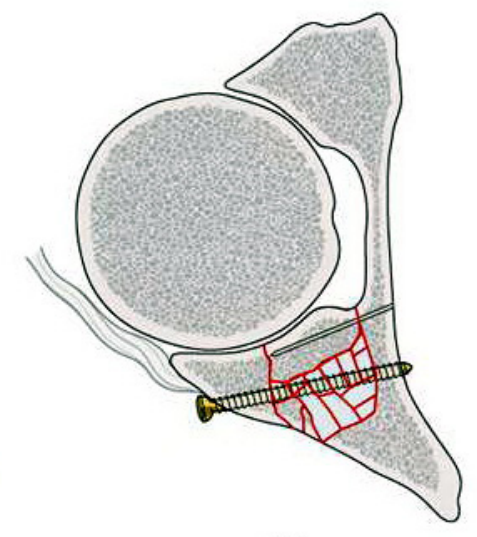

C

Figure2. Diagram showing the technique of elevation and graft impaction of marginal impaction lesion of the posterior wall fracture acetabulum [9].

The postoperative radiographs were examined for reduction, degrees of displacement, quality of fixation and the presence of joint penetration (Figure 3). Clinical and radiological evaluation of the patients after discharge from the hospital in routine visitswere scheduled after two weeks, six weeks, three months, six months, ninth months, and one year then annually until end of follow up. Mobilization of the patients in bed was allowed as soon as pain tolerated, gradually followed by active range-of-motion exercises. The patients were mobilized out of bed using axillary crutches without weight bearing which was delayed in all cases for 3 months.

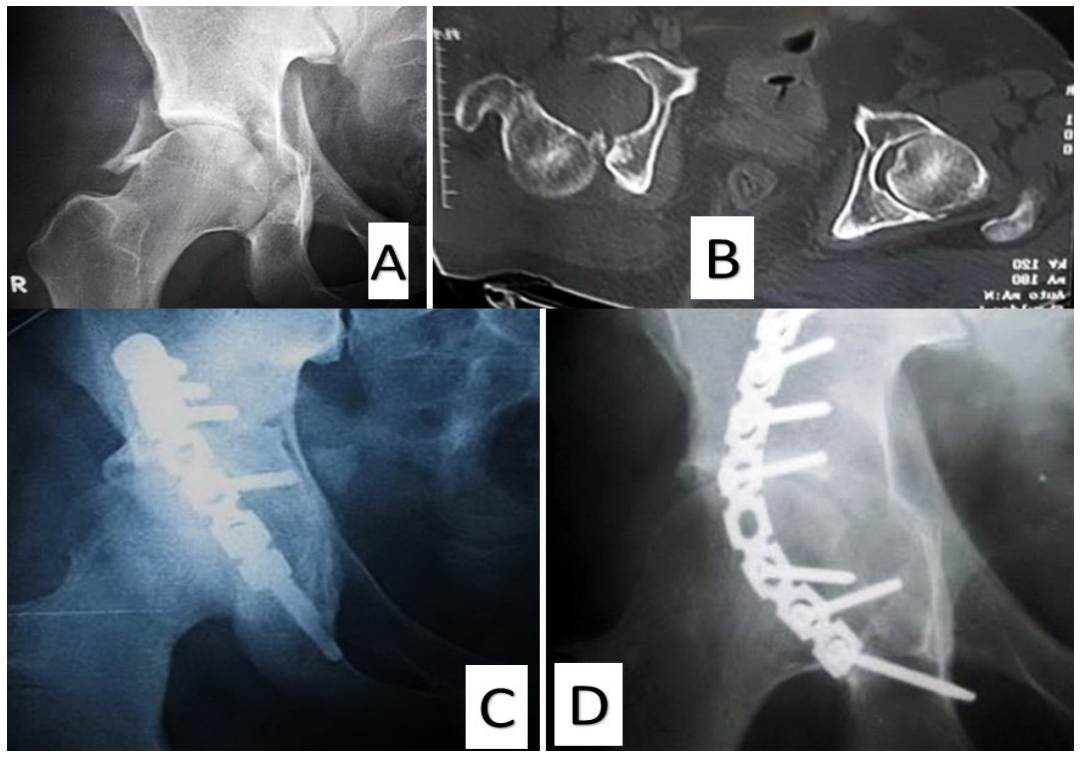

Figure3. Female patient, 35 years old, with right transverse fracture acetabulum associated with posterior wall A) Preoperative X-ray, B) Preoperative C T examination showing fracture dislocation hip, C\& D) Postoperative $x$-ray after internal fixation of fracture (case no. 7). 
After three months the patients were encouraged to gradual full weight-bearing according to union and type of fracture. Physical therapy was then began to get full muscle strength and continued until maximum possible muscle strength and range of motion were regained. The duration of rehabilitation ranged from 9 to 12 months to get the final picture of the patient level of activity and pain relief.

Many of the patients did not return for all scheduled visits, but all attended the final interviewand filled questionnaire and final clinical examinationsto record range of motion, gait and ability to return to the preinjury job state including all complications.

Matta et al. (1986) [2] criteria of reduction were used to evaluate degree of displacement in postoperative $\mathrm{x}$-rayas Anatomical reduction (zero to $1 \mathrm{~mm}$ displacement) , imperfect (2-3 $\mathrm{mm}$ displacement and poor (more than $3 \mathrm{~mm}$ displacement). Serial followup radiographs were examined for loss of reduction, fracture union, implant failure, heterotopic ossification (HO)according to Brooker criteria [10], avascular necrosis of the femoral head according to Ficat criteria [11]; arthritic changes e.g. osteophytes, sclerosis and narrowing of the joint space compared with the contralateral hip. The modification of the system of Merle d'Aubigné and Postel [3] was used for clinical grading and prognosis at final follow up where excellent score (18 points), good score $(15,16$, or 17$)$, fair (13 or 14), and poor results when $(<13)$. For final radiological results Matta criteria [3] Excellent : Normal appearance of the hip; Good: Mild changes, small osteophytes, moderate $(1 \mathrm{~mm})$ narrowing of joint \& minimum sclerosis; Fair: Intermediate changes, moderate osteophytes,moderate $(<50 \%)$ narrowing of joint\&moderatesclerosis; Poor: Advanced changes, large osteophytes, severe ( $>50 \%)$ narrowing of the joint, collapse or wear of the femoral head, and acetabular wear. for functional evaluation were used at final follow up .

\section{STATISTICAL ANALYSIS}

Statistical analysis of the data was performed by an independent biostatistician who was not directly involved with the study.Data were then imported into Statistical Package for the Social Sciences (SPSS version 20.0), and percentages in groups were compared by Chi-square test. Differences between means by ANOVA test. P value was set at $<0.05$ for significant results $\&<0.001$ for high significant result.Correlation studies were conducted by bypearson correlation test .

\section{RESULTS}

The longest follow up period was 36 months and the shortest was 12 months with a mean of 22 months. The mean operative time was $135 \mathrm{~min}$ (range 120-160), and the mean blood loss was $780 \mathrm{ml}$ (range $500-1200$ $\mathrm{ml}$ (Table 1). The quality of reduction according to Matta's criteria was anatomical reduction found 16 cases (80\%), and satisfactory in 4 cases (20\%); (Figure 4).Clinically based on modified Merle d'Aubigné and Postel score, excellent results achieved in 4 cases (20\%), good in 12 cases (60\%), and fair in 4 cases (20\%), but no poor results in this series. The final radiological evaluation of the hip joint according to Matta criteriawas excellent in 6 patients (30\%), good in 10 patients (50\%), fair in $3(15 \%)$ patients and poor in one patient (5\%). The patient with poor results was operated on after 2 years doing total hip replacement (Figure 5)this patient admitted to our hospital after 19 days of injury with neglected dislocation.According to Ficat et al criteria, there were two cases with AVN of femoral head one case of grade II, the other was grade IV and needed total hip replacement 2 years after fracture treatmentdue to financial reasons. Hypertrophic ossification was found in two patients but it was Brooker grade (I) and not affected clinical results.

Table1. Descriptive statistics of the 20 patients.

\begin{tabular}{|l|l|l|}
\hline & Range & Mean \pm SD \\
\hline Age & $21--58$ years old & $32.9 \pm 10.55$ \\
\hline timing (lag days) & 3 days -- 20 days & $7.18 \pm 3.44$ \\
\hline Operation time /minute & $120 \mathrm{~min}--160 \mathrm{~min}$ & $135 \mathrm{~min} \pm 20$ \\
\hline Blood loss/ml & $500 \mathrm{ml}-1200 \mathrm{ml}$ & $916 \mathrm{ml} \pm 282$ \\
\hline Blood transfusion/ml & $500 \mathrm{ml}-1500 \mathrm{ml}$ & $780 \mathrm{ml} \pm 350$ \\
\hline
\end{tabular}


American Research Journal of Orthopedics and Traumatology (ARJOT)

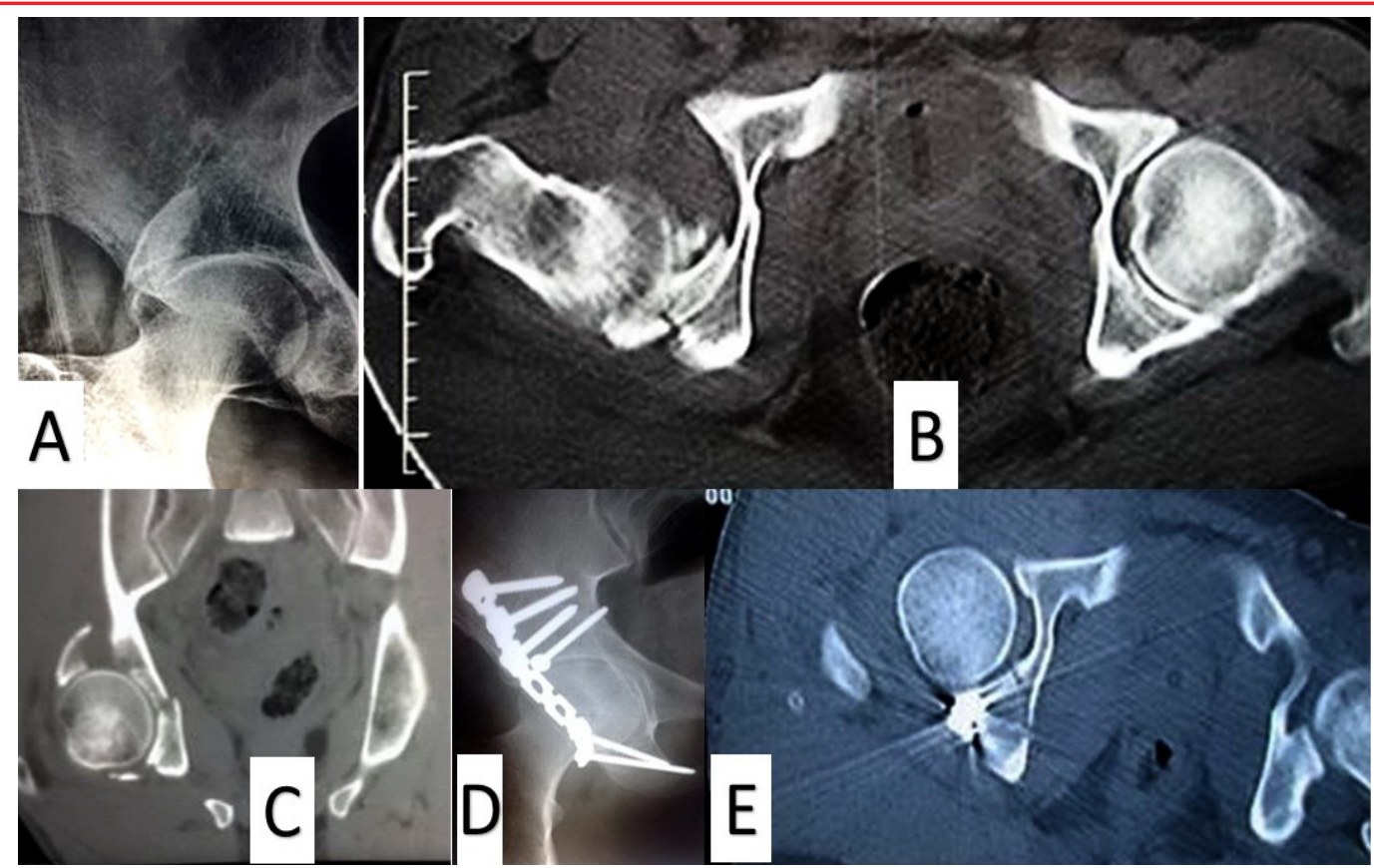

Figure4. Male patient, 33 years old, with right Posterior column and posterior wall fracture dislocation (reduced on urgent basis) with marginal impaction; A) Preoperative $x$-ray; $B \& C$ ) preoperative $C$; $D \& E$ ) postoperative $x$-ray after internal fixation F) C T scan postoperative.

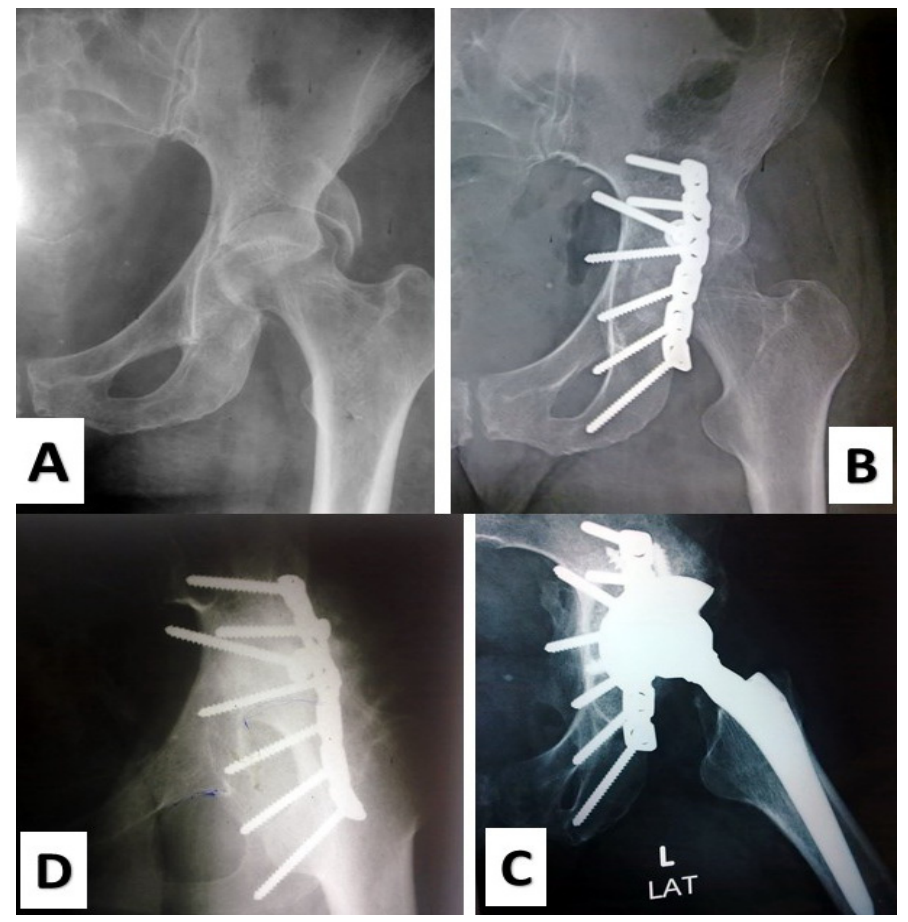

Figure5. Male patient 49 years old with left posterior wall fracture acetabulum with marginal impaction; A) preoperative $x$-ray; $B$ ) postoperative $x$-ray; $C$ ) $x$-ray 18 months postoperative showing $A V N$ femoral head and hip arthritis; $D$ \& E) x-ray after cementless total hip replacement. 
Correlating the clinical scores to age of the patients there were better results in patients with age below 40 years but not highly significant (Table 2). No significant difference between clinical scores in relation to the degree of reduction $(p=0.07)$. Clinical scores did not differ significantly according to sex of the patients either male or female $(\mathrm{p}=0.06)$.

Table2. correlation between clinical scores and other variables.

\begin{tabular}{|l|c|c|}
\hline \multirow{2}{*}{} & \multicolumn{2}{|c|}{$\begin{array}{c}\text { Modified Merle d'Aubigné } \\
\text { score }\end{array}$} \\
\cline { 2 - 3 } & $\mathbf{r}$ & P-value \\
\hline Age & -0.086 & 0.552 \\
\hline Timing (lag days) & -0.169 & 0.242 \\
\hline Blood loss & -0.198 & 0.168 \\
\hline Operation time (hours.) & -0.142 & 0.368 \\
\hline Blood loss & 0.086 & 0.549 \\
\hline Blood transfusion & 0.172 & 0.445 \\
\hline Follow up (months) & 0.042 & 0.700 \\
\hline
\end{tabular}

The complications in this study were found in 3 cases; two cases with superficial infection treated by repeated dressing and parenteral antibiotics according to culture and sensitivity, one patient had postoperative sciatic palsy that improved after 7 months.

\section{Discussion}

The goal of operative treatment of acetabular fractures is to preserve a functional, mobile, painless hip joint. To achieve this goal; you should have anatomic reconstruction of the articular surface, stable and congruent hip joint, early mobilization without endangering fracture stability [12-15]. Many authors report better results up to $80 \%$ good to excellent in early interference within 21 days [1\&3\&16]. Beyond 21 days, definite soft tissue changes occur as scar tissue formation, loss anatomic fit and fracture gaps fill with fibrous tissue and callus formation. These factors result in a more difficult situation for exposure, reduction, and stabilization which decrease the long term results [17-19].In this study all patients were operated within three weeks in a mean time of 10 (3-20)days.Letournel and judet[1] described the term (marginal impaction) and reported it in 16\% of the posterior dislocations in their series. Preoperative C T scan used by Braumback et al [4] and reported23\% incidence in their study. CT was routine evaluation of all cases of fracture acetabulum in this study.

With using postoperative C T scan and 3d reconstruction the fragment of MOI was discovered to be a cause of postoperative incongruency and later hip arthrosis if not elevated and fixed in correct position [8].In this study some difficulties were found during elevation of the depressed fragment because the cancellous surface of the posterior column to which the posterior wall should easily reduce has been altered. If the posterior wall was stabilized without reduction of the MOI, two problems may arise. First, an incongruent defect remains in the posterior acetabulum, which theoretically could lead to instability of the femoral head within the hip joint increasing shear forces which in turn induces articular cartilage degeneration. Second, loss of posterior wall fixation which depends onthe size of the posterior wall, degree of depression of MOI and type of internal fixation as screws fixing the posterior wall fragment can pass directly through the articular surface of the MOI fragment [1\&8\& 20-22].

In this work to avoid these complications, elevation, reduction and defect packing by bone graft taken from the greater trochanter were done before final fixation of column and wall fractures. The results of this study were comparable with other studies as the reduction quality correlates with the clinical results this makes MOI a major prognostic element in fracture acetabulumsince all patients in this series had preoperative CT showing MOI and also they had clinical hip instability, no posterior fracture dislocation of the hip showing MOI is considered stable after closed reduction. 


\section{CONCLUSION}

In the preparation of fracture acetabulum indicated for surgery, preoperative CT is a good tool to diagnose MOI which indicates posterior hip instability and operative technique by elevation, reduction, bone graft packing, and fixation become mandatory to obtain anatomic reduction and favorable outcome. Thistechnique should be completed before final fixation of the main fracture acetabulum.

\section{REFERENCES}

1. Letournel E, Judet R. (1993): Fractures of the acetabulum, 2nd ed. New York: Springer-Verlag, pp 23-24.

2. Matta J.M. (1986): Operative indications and choice of surgical approach for fractures of the acetabulum. Techniques in Orthopedics; volume 1, pp: 13-22.

3. Matta J .M. (1996). Fractures of the acetabulum: accuracy of reduction and clinical results in patients managed operatively within three weeks after the injury. Journal of Bone Joint Surgery (Am), volume 78, pp: $1632-1645$.

4. Brumback R.J, Holt E.S, Poka A.(1990):Acetabular depression fracture accompanying posterior fracture dislocation of the hip. Journal of Orthop Trauma; volume 4, pp:42-48.

5. Pascarella R, Digennaro V, Grandi G. (2011). Osteochondral impaction of the posterior acetabular surface without cortical fracture of any wall or column: an undescribed pattern of acetabular injury. J OrthopTraumatol; 12:101-105.

6. Alonso JE, Volgas DA, Giordano V, Stannard JP (2000). A review of the treatment of hip dislocations associated with acetabular fractures. ClinOrthopRelat Res; 377:32-43.

7. Giannoudis PV, Kanakaris NK, DelliSante E, Morell DJ, Stengel D, Prevezas N. (2013). Acetabular fractures with marginal impaction: mid-term results. Bone Joint J.; 95-B: 230-238.

8. Patrícia M S, Vincenzo G, Flávio G, Antônio A. O. S, José A. G, and Marcus V. D.(2015). Marginal Impaction in Posterior Wall Fractures of the Acetabulum. Am J of Roentology, vol 204(no 4); w470-474.

9. Keith Mayo, Michel Oransky, Pol Rommens, Carlos Sancineto (2016): www. AO foundation.org. Acetabulum - Reduction \& Fixation - Kocher-Langenbeck - Posterior wall - AO Surgery Reference.

10. Brooker AF, Bowerman JW, Robinson RA, Riley LH Jr (1973). Ectopic ossification following total hip replacement; incidence and a method of classification. J Bone Joint Surg Am 55:1629-1632.

11. Ficat P, Arlet J (1980). Necrosis of femoral head. In: Hungerford DS (ed) Ischemia and necrosis of bone. Williams \& Wilkins, Baltimore, pp 53-74.

12. Moed B. R. ,Ajibade D. A. and Israel H. (2009): Computed Tomography as a Predictor of Hip Stability Status in Posterior Wall Fractures of the Acetabulum, Journal of Orthopedic Trauma Volume 23, Number 1, pp:7-9.

13. Helfet D. L., Beck M., Cautier E. (2003). Surgical techniques for acetabular fractures. In: Fractures of the pelvis and actabulum. The3rd edition chapter $28 \mathrm{pp}: 534-539$.

14. Giannoudis P. V. ,Grotz M. R. W., Papakostidis C., Dinopoulos H. (2005). Operative treatment of displaced fractures of the acetabulum J Bone Joint Surg [Br] 87-B: 2-9.

15. GiordanoV.,Amaral N. and Franklin C., (2007). Functional Outcome after Operative Treatment of Displaced Fractures of the Acetabulum: A 12-month to 5-year Follow-up Investigation. European Journal of Trauma and Emergency Surgery volume ( 5),pp:520-527. 
16. Mears DC, Velyvis JH and Chang CP. (2003). Displaced acetabular fractures managed operatively: indicators of outcome. ClinOrthop; 407:173-86.

17. Leucht P1, Castillo AB, Bellino MJ. (2013): Comparison of tricalcium phosphate cement and cancellousautograft as bone void filler in acetabular fractures with marginal impaction. Injury, Jul., 44 (7): 969-74.

18. Hong-Fei Shi, Jin Xiong, Yi-Xin Chen, Jun-Fei; Wang and Yin-He Wang (2014): Radiographic analysis of the restoration of hip joint center following open reduction and internal fixation of acetabular fractures: A retrospective cohort study. BMC Musculoskeletal Disorders, 15: 277.

19. Briffa N., Pearce R., Hill A.M (2011): Outcomes of acetabular fracture fixation with ten years' follow-up. J. Bone Joint Surg. Br., 93: 229-36.

20. Patrícia Martins E Souza1, YincenzoGio- Rdano, FlávioGoldsztajn, Antônio A.O. Siciliano, José A. Grizendi and Marcus V. (2015): Marginal Impaction in Posterior Wall Fractures of the Acetabulum, American Journal of Roentgenology, 204: W470-W474, 2015.

21. Giannoudis P.V., Tzioupis C., Papathanas- Sopoulos A., Obakponovwe O. and Roberts c.(2010): Articular step-off and risk of post-traumatic osteoar- thritis: Evidence today. Injury, 41: 986-95.

22. Pascarella R; Digennaro V. and Grandi G. (2011):Osteochondral impaction of the posterior acetabular surface without cortical fracture of any wall or column: an undescribed pattern of acetabular injury. Journal of Orthopaedic Traumatology, volume 12, pp: 101-105.

Citation: Yousuf M Khira, "Surgical Treatment of Marginal Osteochondral Impaction in Acetabular Fractures". American Research Journal of Orthopedics and Traumatology; Volume 1, 2016; pp:1-8

Copyright (c) 2016 Yousuf M Khira, This is an open access article distributed under the Creative Commons Attribution License, which permits unrestricted use, distribution, and reproduction in any medium, provided the original work is properly cited. 